\title{
0 imbricamento do espaço e do tempo nos filmes $O$ Espelho e Amor
}

\section{Patricia Moran e Carolina Gonçalves}

\section{Resumo}

Ao apresentar e discutir as estratégias de construção espaço-temporal nos filmes Amor, de Michael Haneke, e O Espelho, de Andrei Tarkvoski, buscamos problematizar a utilização do planosequência e relacionar estratégias estilísticas que fazem do imbricamento do espaço e do tempo recurso mnemônico.

\section{Palavras-Chave}

Espaço. Tempo. Plano-sequência. Michael Haneke. Andrei Tarkovski.
Patricia Moran I patriciamoran@usp.br Doutora em Comunicação e Semiótica pela Pontifícia Universidade Católica de São Paulo - PUCSP, Brasil. Professora do Curso de Graduação em Audiovisual e do Programa de PósGraduação em Meios e Processos Audiovisuais da Universidade de São Paulo - USP, Brasil.

Carolina Gonçalves I divinaclementina@gmail.com Mestre em Poéticas e Técnicas Audiovisuais pelo Programa de Pós-Graduação em Meios e Processos Audiovisuais da Universidade de São Paulo - USP, Brasil.
A construção espaço-temporal em $O$ Espelho (1975), de Andrei Tarkovski, e Amor (2012), de Michael Haneke, é nossa ponta de lança para a análise do uso de recursos expressivos como 0 plano-sequência na estruturação narrativa. A aproximação por contraste dos filmes, distantes em suas propostas figurativas, narrativas e vínculos com o real, problematiza o espaço como dimensão temporal, implicando espaço e tempo na matéria narrativa e expressiva, gesto presente nos dois. Para Gilles Deleuze, de O Ato de Criação (1999), o cinema é constituído de blocos de tempo/espaço. Nesses filmes, o jogo com e entre as dimensões como o espaço e o tempo estruturam os blocos espaço-temporais, ora de maneira disruptiva, de modo a fazer não coincidirem mudanças do espaço e do tempo em continuidade em O Espelho, ora aprisionando tempo ao espaço e vice-versa. São ainda desestabilizadas supostas ontologias do plano-sequência e seus índices de continuidade espaço-temporal da imagem em movimento. Pelo jogo com o espaço, seja ele do presente, datado historicamente ou atravessado pela subjetividade, ou seja, contando com a seletividade da memória, o tempo ganha 
concretude e movimento, sendo mais ou menos dilatado. A duração dos planos, do desenrolar das ações e os movimentos de câmera estruturam a cadência filmica. As passagens e os intervalos entre os planos situam a ação em espaço cuja existência é fílmica. Mídia baseada no tempo do inglês time based media -, o cinema faz da imagem e do som campo para a espacialização da experiência fílmica.

Amor, de Haneke, e O Espelho, de Tarkovski, enredam o espaço na construção do tempo e, simultaneamente, evidenciam o espaço como dimensão temporal. Amor é um filme em flashback sobre os últimos dias do casal Laurent em amplo e sofisticado apartamento parisiense. O Espelho é um mergulho nas memórias do protagonista através de uma espiral pelo tempo, eterno retorno no qual se embaralham fatos e memória. A alternância entre 0 preto $\&$ branco, a imagem colorida e as imagens de arquivo acentuam a narração disruptiva, criando ilusões sobre a relação entre a cor e as épocas apresentadas no filme pela memória e pelas imagens de arquivo. A atriz Margarita Terekhova, nos papéis de mãe e esposa, instaura vetores de estilhaçamento temporal em diversas aparições ruidosas. 0 filme se passa antes da guerra, na década de 1930, durante a Segunda Guerra e na década de 1960. Ao jogar com épocas e acontecimentos históricos, se imprime a qualidade das sensações e dúvidas de Tarkovski, uma testemunha e ator da história e das fabulações livremente orquestradas neste filme autobiográfico, que se autonomiza do realizador e faz um ajuste com suas lembranças.

Já em Amor, a vida de um casal de idosos é medida do tempo biológico e do final certo da existência humana. No filme de Haneke, a crescente perda das funções vitais de Anne Emmanuelle Riva - mostra o tempo impresso no corpo, construindo passo a passo, a fragilidade e a decadência física do passar dos anos, o que resulta, via de regra, em dependência do outro. Nem 0 amor, néctar da existência decantado no romantismo e em folhetins de toda ordem, amaina a aspereza das marcas do tempo. Pode-se encurtar o sofrimento e abandonar o curso da existência, como desejava Anne, a senhora Laurent, ao usar o que lhe restava de forças na luta contra a compaixão. $0 \mathrm{Sr}$. Laurent, por sua vez, testemunha e experimenta simultaneamente a degradação no próprio corpo e a física e a mental da esposa. As dimensões do apartamento parisiense e a decupagem localizam o público em privilegiado lugar de testemunha.

\section{0 espaço em Amor}

0 filme se inicia diante de uma porta fechada. A câmera permanece fixa no interior do apartamento, como se estivesse à espera de socorro que vem violar, o que descobrimos mais tarde ser um apartamento-mausoléu. Barras de ferro, homens uniformizados e vizinhos preocupados impõem-se com força e violência na porta de entrada neoclássica de duas faces. 
Com a câmera, presencia-se 0 arrombamento da porta. No vestíbulo de entrada, do lado de dentro do apartamento, segue-se para a direita com quem parece ser o responsável por coordenar a operação. A face direita do amplo hall de entrada é revelada à câmera, que continua em ângulo de aproximadamente $90^{\circ} \mathrm{em}$ relação ao plano inicial, em que há uma porta lacrada. Prossegue percorrendo a casa com o bombeiro, entramos em outro espaço contíguo em relação ao anterior, há outra porta lacrada à esquerda. 0 cheiro insuportável da sala obriga 0 agente policial a abrir duas janelas do cômodo, ele se dirige para outra sala à direita, não chega a entrar, mas dá tempo ao público de ver na sala um piano de cauda. 0 policial volta para a entrada principal, a câmera 0 acompanha até chegar à primeira porta fechada, a qual, arrombada pelos bombeiros, revela uma senhora morta com flores sobre seu peito. Ao acompanhar a câmera e a equipe de resgate, 0 espectador conhece 0 apartamento.

0 espaço em Amor é topográfico, amplos corredores, salas e portas são cruzados em diversas direções, com a câmera em movimento ou fixa. Jean-Louis Trignant dá vida a um Sr. Laurent com a perna esquerda pesada. Suas andanças pelo grande apartamento produzem a espera da consecução dos passos. Sucessivos travellings, pans e câmeras fixas dão a conhecer 0 apartamento no qual 0 espectador permanecerá enclausurado pelas suas próximas horas.
0 filme prossegue com a única sequência ambientada no exterior do apartamento. A próxima entrada neste espaço será com os proprietários. 0 tema do arrombamento retorna através de uma fechadura forçada, mencionada pelos proprietários na volta de um concerto. Os espectadores já conhecem o local (sem autorização de seus donos) e conseguem se orientar minimamente no local. Um novo posicionamento de câmera, no eixo inverso ao da cena anterior, revela o banheiro e a cozinha localizados no mesmo corredor apresentado na cena anterior, quando a equipe de resgate chegou. Resta, para se conhecer do apartamento, um cômodo ao lado da cozinha, algo como um escritório ou estúdio, um quarto de estudos, supostamente destinado ao protagonista.

A arquitetura é elemento narrativo em Amor. Vai-se atualizando a noção geral do espaço por onde a ação se desenrola conforme a câmera percorre, em sucessivos set ups, o ambiente. Dessa forma, o espectador conhece a geografia e a sonoridade do apartamento, partilha a intimidade do local pela familiaridade com 0 espaço. Domina o espaço visível e acompanha 0 personagem no seu tempo e em suas mudanças em cena, os espaços off se tornam conhecidos e presentes visualmente. A queda de Anne é som do baque e do grito, ela se encontra no outro extremo da casa; Georges está na cozinha, ouve-se um som seco. Permanece em suspenso o que teria, de fato, acontecido 
e as consequências para a saúde frágil da senhora. Aguarda-se 0 Sr. Laurent percorrer 0 apartamento com seus vagarosos passos para se conhecer os desdobramentos do ruído. A duração do plano traduz as dificuldades do velho senhor.

A suspensão temporal é provocada pelo grito de Eva (Isabelle Hupert), filha do casal. Ela foi ver a mãe, está fora de quadro, a câmera permanece com seu pai na biblioteca sem se mover até que ela volte. Como o ponto de vista das cenas é do Sr. Laurent, a sua espera é cega na primeira situação, ou seja, quando a senhora cai, na segunda, é fruto de seu conhecimento da filha. Na primeira, ele não sabe 0 que aconteceu e corre para verificar; a segunda expressa a solidão do Sr. Laurent, a distância de sua filha assustada por estar alheia ao estado de saúde da mãe. Há uma terceira situação entre Eva e Sr. Laurent, em que a ação se desenrola simultaneamente em dois espaços. Ela toca a campainha fora de quadro, não a vemos, ele fecha a porta do quarto da esposa, dá descarga, fecha a porta do banheiro e, finalmente, abre a porta da rua. Eva escuta a ação de uso do banheiro, testemunhamos a narração da mentirosa ida ao banheiro pelas imagens. 0 isolamento de Georges, o não entendimento pela filha da dimensão moral da situação produzida pela doença, tem na separação física, na não comunhão do espaço visível um ponto de afirmação da distância emocional, da impossibilidade de se compartilhar a existência, mesmo com a filha.

0 filme Amor se desenrola em tempo presente. Um presente habitado pelos potenciais caminhos narrativos apontados, principalmente, pelo desenrolar da doença da senhora. 0 diretor restitui ao espaço figurativo e bidimensional da tela de cinema as qualidades do espaço "quinestésico". Aumont problematiza 0 espaço em sua dimensão material, construída visualmente pelo tempo do cálculo e de sua apreensão. Distingue duas naturezas de espaço:

\footnotetext{
"aquele do toque e do movimento, infinito, isotópico, homogêneo, tridimensional cujo modelo rigoroso é o espaço cartesiano. E o espaço visual, não infinito, não isotópico, não homogêneo, cuja tridimensionalidade é imaginária; o modelo geométrico dele é duvidoso e é precisamente em sua procura que se obstina, de início, a fantasia" (AUMONT, 2004, p. 147).
}

Haneke carrega o espaço fílmico com marcas eloquentes do espaço físico, ou seja, do espaço cartesiano constituído pela homogeneidade e unidade visual. A intimidade com a casa e os possíveis caminhos a serem percorridos estão indicados na rigorosa decupagem e na relação dos personagens com o lugar. Preso no apartamento, 0 espectador intui direções a serem tomadas naquele espaço amplo e opressivo, pois nunca se sairá dele, como sabemos desde 0 início. Já a linearidade do desenrolar dos acontecimentos e a utilização 
do espaço off, seja do som ou da imagem,

evidenciam dúvidas e certo devir ${ }^{1} .0$

anunciado e inevitável fim da senhora Laurent

está prenhe de tempos. A leitura de Deleuze

do tempo explode a linearidade temporal, ao

subentender a experiência temporal como

transversal, simultaneamente ocupada

pelo passado e buscando o futuro, pois,

segundo o autor: "não há presente que não

seja obcecado por um passado e por um

futuro, por um passado que não se reduz

a um antigo presente, por um futuro que

não consiste num presente por vir. Compete

ao cinema apreender o passado e 0 futuro

que coexistem com a imagem presente"

(DELEUZE, 2005, p. 52). 0s gestos do

senhor Laurent para com a senhora, seu

cuidado e sofrimento carregam a longa vida

partilhada e a concretização do terrível

futuro que se anuncia. 0 cuidado se justifica

pelo amor, como indica o título, pelo passado

partilhado. A perversidade presente em

outros trabalhos do diretor aqui tem no amor seu lugar. A situação narrativa é fruto da pressão do futuro, anunciado no início do

filme, e de uma trajetória passada. A leitura

de Deleuze sobre a coexistência do passado

e futuro no presente traz uma dimensão do

tempo cinematográfico recorrente em Amor.

\section{Espaço-tempo em espiral}

O Espelho é tecido pelo tempo da memória, um tempo lacunar e não linear. Recursos expressivos do cinema como o plano-sequência, normalmente índice de continuidade espaço-temporal, chegam a habitar duas épocas neste filme de Andrei Tarkovski. 0 espaço é atravessado por acontecimentos de tempos imemoriais na voz over recitando os poemas de Arseny Tarkovski, pai de Andrei, e na locução do personagem principal, representação da biografia do diretor. A poesia de Arseny, repleta de imagens sinestésicas, atribui qualidades poéticas impalpáveis a situações e pessoas, como no texto de abertura. Como lembranças casuais, o filme como um todo é poroso e onírico, caminha por saltos e associações, o narrador está doente; em seus últimos dias de vida relembra o passado, delírio encarnado cinema. Entre as memórias pessoais da infância e da adolescência, de sua mãe, da Segunda Guerra Mundial e de um doloroso divórcio, emergem momentos que contam a história da Rússia em uma espécie de quase flashbacks, com reencenações sobre 0 impacto da guerra na infância. Imagens de arquivo pontuam $O$ Espelho com o êxodo de crianças espanholas fugindo da ditadura franquista, à tropa russa atravessando a neve na Segunda Guerra.

0 vocábulo devir atravessa a filosofia desde Aristóteles, passando por Hegel e Heidegger, em cada época e autor tem distinta acepção. Adotamos essa visão filosófica na perspectiva da apropriação de Nietzsche por Gilles Deleuze. Relacionase a mudanças, a potências de mudança, de transformação presentes na situação inicialmente dada, cuja realização pode adotar distintos vetores. A mudança, a ocupação de outro lugar. Com existência empírica, devires demarcam territórios sociais, máquinas de desejo e potências. Ao longo de sua obra, e com Félix Guatari em Mil Platôs encontramos miríade de proposições sobre 0 devir. 
Em seu livro Esculpir o Tempo, ao mencionar 0 ponto de partida para a realização de $O$ Espelho, Tarkovski deixa claro tratar-se de acontecimento da memória: "0 filme seria a história de seus pensamentos (do protagonista) sem que este aparecesse em momento algum - pelo menos da forma como se costuma fazer num filme tradicional" (TARKOVSKI, 2002, p. 30). E o fluxo da narrativa segue a memória, ou, pelo menos, 0 livre rememorar. Caminha por associações. 0 fogo de uma casa traz o fogo da outra. 0 medo em um tempo é associado ao medo de outro. A lembrança da menina com a boca machucada, uma imagem de amor do narrador, nos conduz para a guerra. A câmera lenta, a beleza da menina, o branco de sua pele e da neve conferem improvável poesia à dureza da época. 0 título do livro de Tarkovski, Esculpir o Tempo, indica a centralidade do tempo em sua obra, aproxima o gesto do cineasta ao do artista plástico. A marca do diretor, defendida no livro e praticada nos filmes, está na construção de passagens de tempo em cada plano. Assim como Haneke, ele instaura passagens no plano ao criar expectativas sobre a mudança da situação. Se a espera não muda a situação, pelo menos o faz com a relação com o filme. Malgrado as abissais diferenças entre os diretores, cada qual à sua maneira, faz do plano um lugar de sucessão e não de situação acabada por ação única. 0 plano tampouco é fragmento de situação para se emular a continuidade espaço-temporal, para acelerar 0 tempo ${ }^{2}$.

As associações de ideias trazem passagem de tempo com alternância entre épocas, escolha deliberada por Tarkovski da estrutura do filme. A menção à morte de Elisabeth, amiga de Macha (mãe do narrador), motiva a visita ao passado e exploração da relação entre as duas. A imagem volta a ser em preto e branco, o medo provocado por Stalin é vivido por Macha, revisora em uma gráfica. A história política da União Soviética é anunciada na violência do vigilante à entrada do jornal. Ele pergunta: 'Por que tanta pressa?' Ela retruca: 'Achas que tenho medo'. A resposta dela é uma leitura para uma espécie de coação presente na pergunta, evidenciada pela postura e fala de Macha. 0 medo de haver errado na revisão a deixa transtornada, excessivamente fora de si. 0 descontrole da personagem é valorizado para a exposição do medo e da violência relacionados à situação política e ao desequilíbrio de Macha. A instabilidade emocional fora mencionada pelo marido, pelo filho e, deselegantemente, pela própria Elisabeth.

Como em Amor, o filme começa esclarecendo seus pressupostos estilísticos e descontinuidades. Uma TV vermelha é ligada por um garoto, permanece fora do ar. A cena é invadida por voz over, dando 
continuidade ao plano seguinte em preto e branco, no qual se colocam outro contexto e tempo, temos uma sessão de hipnose que recupera a gagueira de Yuri Alexandrovitch.

A sobreposição de tempos é reforçada pelo uso de planos-sequência, o movimento da câmera em vez da continuidade espaço-temporal, figura que 0 consagrou historicamente, emula a continuidade espacial para construir a descontinuidade temporal. 0 plano-sequência continua causando frisson entre realizadores e público, seja pelo virtuosismo demandado, pelo desafio a ele relacionado, seja como recursos para manter 0 público como "testemunha" dos acontecimentos exibidos, em tese, sem cortes. Thomas Elsaesser, ao se referir ao cinema contemporâneo, especialmente o que ele denomina world cinema, aponta mudanças no plano-sequência, um dos "marcadores tradicionais de uma estética realista" (2015, p. 38). Hoje, há o uso inconsequente do plano-sequência, ou seja, sem qualquer "consequência" ou desdobramento narrativo. Estes não promovem atrito nem encontro sensível criando situações reveladoras da proximidade e/ou distância entre coisas e pessoas, 0 mundo material pelo mundo cinematográfico, ou seja, são planossequência em que a duração encerra-se em si, trata-se de demonstrações de virtuosismo técnico. Há ainda Michael Haneke, Abbas Kiorastami e Hou
Hsiao-Hsien, para ficarmos apenas nos autores mencionados por Elsaesser (2015: p. 38), que reinventam com potência os planos-sequência. Haneke ${ }^{3}$, como vimos no início deste ensaio, faz da decupagem, da prisão de personagens e espectador em praticamente um único cenário um mecanismo de controle para se alcançar 0 desconforto projetado.

Tarkovski lança mão de planos-sequência com objetivos distintos ao longo de sua cinematografia, vamos nos deter ao seu uso em O Espelho. Há uma cena logo no começo do filme, iniciada com uma voz over masculina chamando Dunia. Aflita, a voz pergunta o que aconteceu, retira Macha do torpor e a conduz para fora da casa, ela cruza as crianças. Volta logo e avisa aos pequenos sobre 0 fogo, deixa novamente a casa à mãe, agora acompanhada pela câmera e pelas crianças. Após cruzarem a porta de saída, se dirigem à direita cruzando outra porta, cuja metade superior é de vidro. A câmera atrás da porta com vidro observa os meninos que, de costas, olham o fogo, sai pela mesma porta outro menino, de outra época, e a câmera 0 acompanha, teremos outro fogo. 0 figurino e 0 corte de cabelo dos meninos são índices da mudança de época. A mãe usa a mesma roupa. Esta é uma cena desconcertante. 0 primeiro incêndio está referenciado no filme, adiante saberemos ter acontecido em 1935 na apenas do cinema clássico, mas como do primeiro cinema, a recuperação não inocente do espaço cinematográfico clássico. Como os termos do debate extrapolam nossos objetivos, mesmo se tratando de espaço, optamos por evitar esta rica seara relacionada ao plano-sequência. 
granja, mesmo ano em que o pai deixou a família. 0 segundo menino é Ignate pequeno, filho do personagem principal. 0 fogo visado no outro lado da porta com os meninos de costas não se fecha como sentido. Como nos Hai Kai, poemas japoneses admirados por Tarkovski (2002, p. 123), prevalece 0 vago, a sobreposição de situações cuja relação está simultaneamente, dada pela proximidade, e em aberto, pela não construção de relação direta.

Ao decidir enfrentar suas fragilidades, sua história pessoal e as guerras envolvendo a União Soviética, Tarkovski se empenha na rigorosa reconstituição da casa de sua infância. A partir de fotos, refaz a casa e os jardins, replantando o trigo, tradução do sentimento dos personagens ao longo do filme. 0 tempo se concretiza no espaço, é uma dimensão do espaço, como temos dito. Para Anheim, o pensamento é visual e a memória espacial (Anheim, apud, Aumont, 140). A memória, o mergulho em sentimentos e situações passa pelo espaço. As lembranças chamam espaços, mesmo que distorcidos. 0 próprio Tarkovski reconhece uma espécie de efeito psicanalítico, efeito redentor provocado pelo filme em sua vida, situação esta assentada na casa, no espaço. Após realizar o filme, deixou de sonhar com a casa em que viveram durante anos (2002, p. 152).

0 espaço em $O$ Espelho não é referencial, pelo contrário, como temos dito, é simbólico, uma construção filmica das memórias dos personagens, incluindo situações de pura fantasia e poesia. Andrei utiliza a poesia de Arseny para situar seu "espelho":

Todos os encontros, tal qual uma epifania, nos faziam ver que estávamos sozinhos no mundo. Você era mais leve do que a asa de um pássaro. Você descia os degraus... e me levava pelos lilases fluídos à outra parte, com você, do outro lado do espelho.

0 espelho aqui é passagem e também se relaciona ao espaço, demarca dois lugares, dois lados.

0 outro lado mencionado por Arseny povoa 0 folclore de diversos países europeus. É lugar relacionado à alma, à morte, a crendices sobre mau augúrio, como o azar do vidro quebrado, ou a exigência de se cobrirem espelhos quando alguém faleceu em uma casa. Baltrusaitis, em sua história do espelho, aponta os extremos opostos ocupados pelo espelho ao longo dos tempos, de fonte de verdade à fabricação de mentira. Seu uso recorrente na arte ocupou espetáculos de prestidigitação de "Herón de Alejandría (sec. II AC.) a Athanasius Kircher (1646) e Gaspar Schott (1647)" (BALTRUSAITIS: 1978, p.12). Baltrusaitis destaca ainda as lendas e especulações originadas dos tratados catóptricos, remontando a longa tradição do espelho como lugar de revelação do invisível. Jean Cocteau explorou magistralmente 0 espelho como passagem entre mundos em Sangue de um Poeta (1930/32), e entre vida e morte em Orfeu (1949). Cocteau joga com deslocamentos de sentido, em transmissão de rádio no início de Orfeu quando o locutor, em tom grave, sugere que "seria melhor se os espelhos refletissem mais", quebra-se aí o espelho, selando-se o destino fatal 
do personagem.

0 espelho é incorporado por Tarkovski à história, não como elemento sobrenatural, é uma das figuras utilizadas na construção das espirais do tempo que se rompem e realimentam. A ruptura é do desenvolvimento narrativo de um filme não calcado em pressupostos realistas, mas de um realismo psicológico, da memória. É frequente a suspensão da cena em desenvolvimento, se não suspensão, pelo menos o desvio. A sucessão de situações não são desdobramentos actanciais ou temporais, são acontecimentos, movimentos muitas vezes exacerbados por uma câmera lenta ou pela pungência da natureza em chuvas e ventos eloquentes. As crendices e mitologias relacionadas ao espelho, bem como o tratamento a ele conferido por Tarkovski no filme a ele homônimo lhe imputam diversos lugares. De recurso para se estabelecer dois tempos em um mesmo plano, a estratégia para reforçar a dimensão temporal do espaço a partir de associações por contiguidade.

Logo no início do filme, há uma cena exemplar sobre a construção do tempo, trata-se de um ponto de vista do narrador quando criança. Este chama pelo pai saindo da cama, olha para 0 cômodo ao lado no qual vemos, de soslaio, uma roupa atirada cruzando o quadro, uma peça branca voando. 0 pai está lavando o cabelo da mãe, ela fica só no quadro, um zoom in e travelling out mostram a casa carcomida. Começa a escorrer a água no interior da casa, aos poucos a tinta e pedaços de reboco desabam. Não se trata de nenhuma tragédia, mas de uma situação poética, de uma imagem subjetiva. A água lava a casa $\mathrm{e}$ a senhora, ela brinca enquanto a casa cai, se dirige a outro cômodo, agora sem relação com os lugares até então vistos. Ela coloca o echarpe, a câmera se movimenta e temos uma imagem duplicada em um espelho. Corte para ela vista de frente, contraplano, uma velha mulher olha através de um espelho. A velha mulher em posição semelhante é ela no futuro, é a mãe de Tarkovski.

Entre vidros e espelhos, 0 fantasioso e poético universo de água lavando a casa aproxima o tempo pelo espelho. Travelling e panorâmicas ${ }^{4}$ usam texturas e fundos pretos para desorientar, para tornar as passagens imperceptíveis ao espectador. A sequência inicia-se na personagem em uma situação, e a unidade espaço-temporal comumente relacionada à sequência cinematográfica é rompida. 0 espelho não apenas duplica 0 espaço, neste caso, inclui outros tempos. Delicados primeiros planos fecham a sequência, ela desembaça 0 espelho para ver melhor, para se ver melhor, temos a mão jovem, em um rosto de senhora no espelho. No último plano, uma mão se aquece no fogo e ouvimos Alexi adulto atender ao telefone. A câmera caminha no apartamento urbano. Ele 
comenta ter acabado de sonhar. "A propósito, quando foi que papai nos deixou, em 1936 ou 1937? Foi em 1935, responde a mãe. E o incêndio, quando foi que a granja queimou? Também em 1935." Não há qualquer indicação precisa sobre esta linda e fantástica cena se tratar de um sonho, mas como ele constantemente oferece informações sequencialmente, como continuidade do ato de se assistir ao filme, fica a sugestão de se tratar de um sonho.

\section{Figuras 1 a 12: Espelho como passagem}
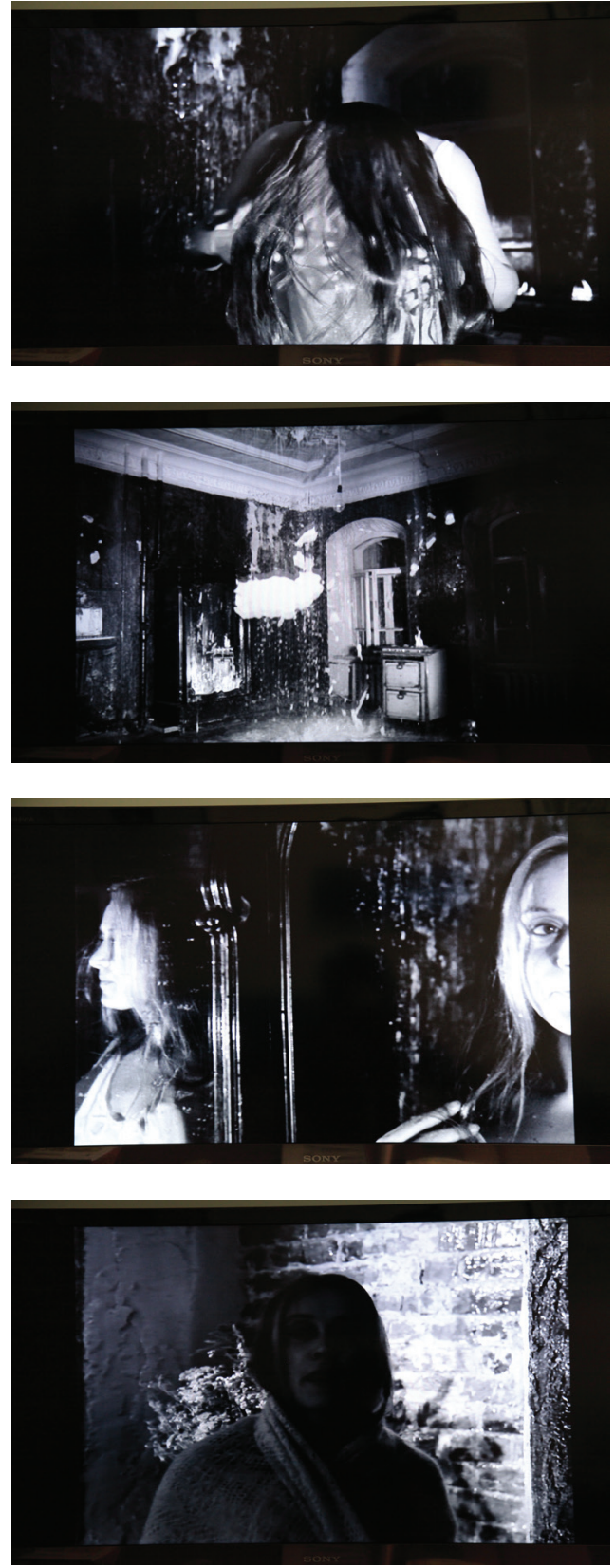
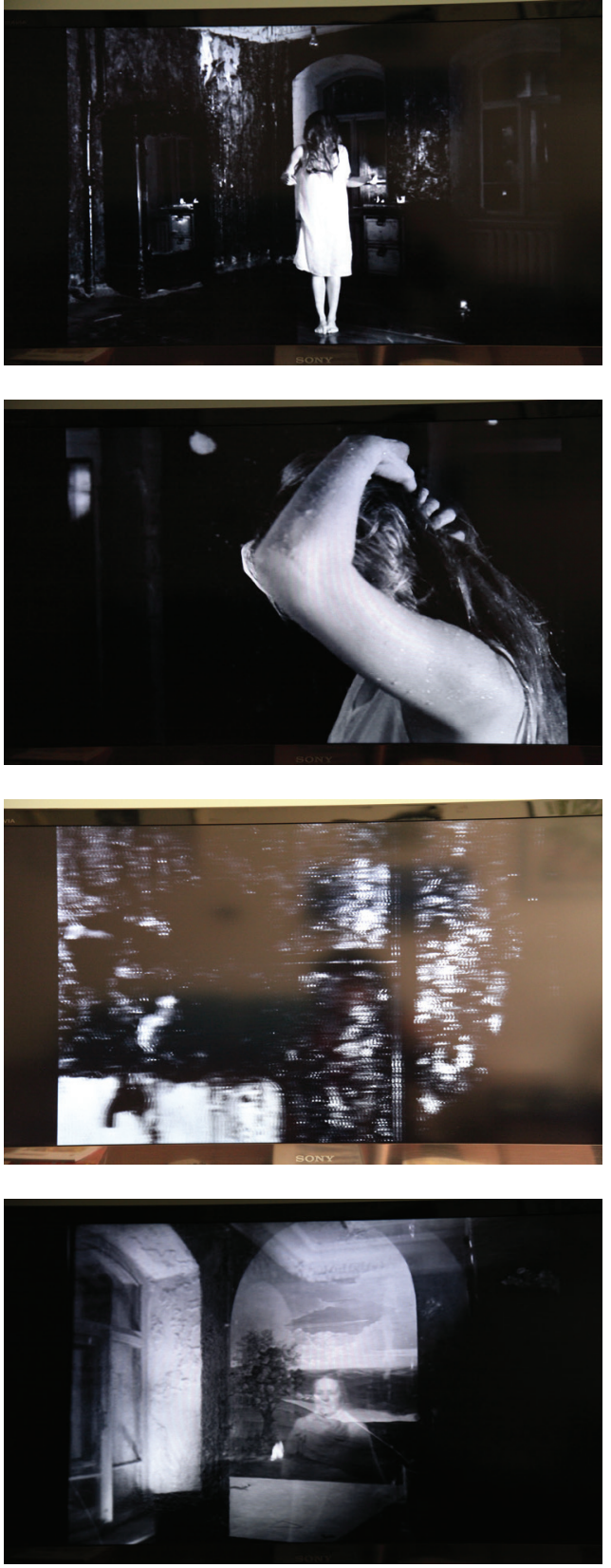

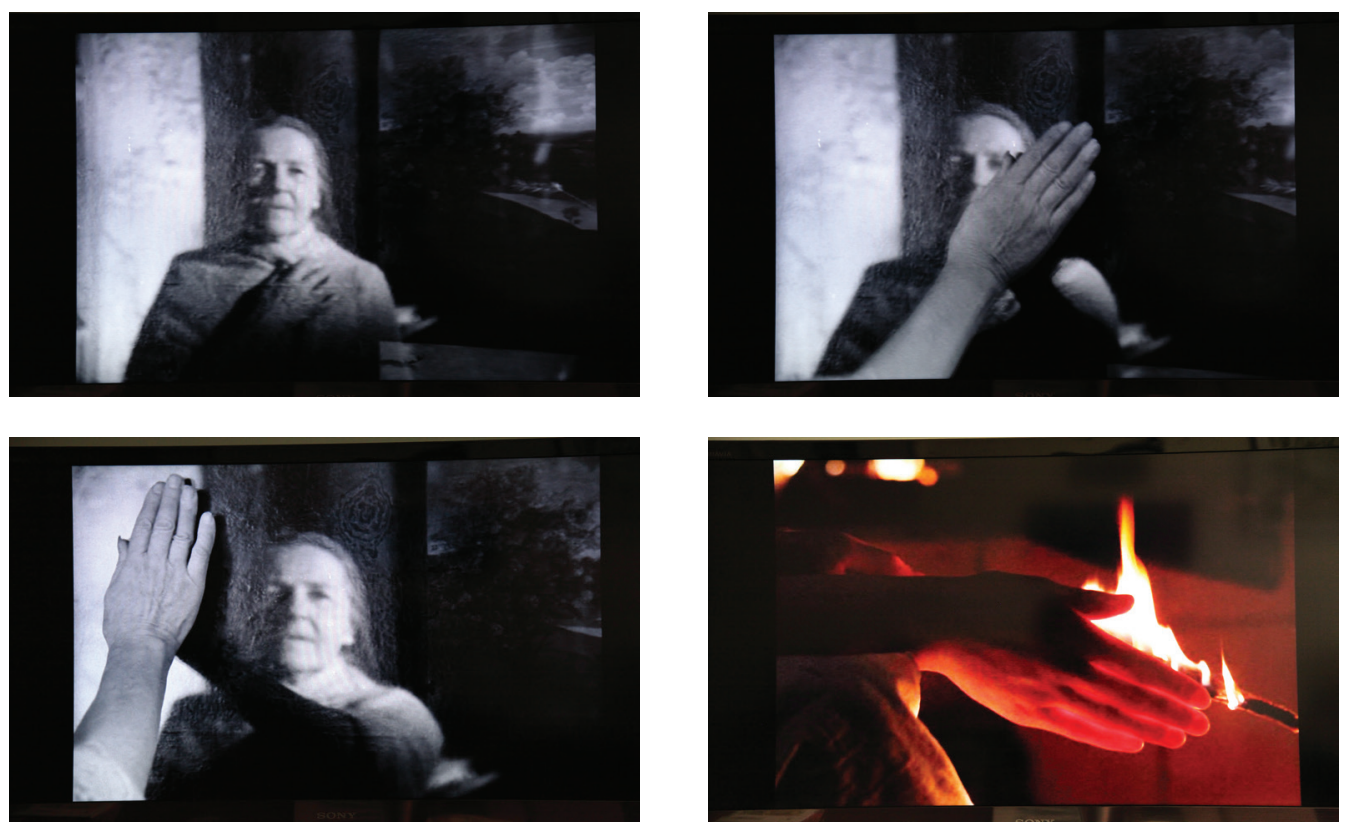

Fonte: Frames retirados do filme 0 Espelho

0 espelho é uma alegoria da visão exata, da perfeição e de duplos como muitas vezes indicado no filme de Tarkovski. Joga-se com a ilusão especular $^{5}$ ao se colocar a mesma atriz para duas personagens. Mãe e esposa são por si só um duplo usado por Tarkovski com liberdade poética, pois a imagem especular existe apenas com a presença do outro. A imagem refletida no espelho não é signo, não é algo em si, duplica o espaço visível com um jogo ótico. A duplicação é do mesmo, não do outro. São recorrentes no filme diálogos sobre semelhanças entre membros de uma mesma família, a ex-esposa e a mãe, a mãe dele e ex-esposa, ele e 0 filho Ignate. 0 filme aponta possibilidades de se fugir a este destino, mas a memória parece falar mais alto e chama como modelo a figura parental.

A tênue narrativa enfatizada anteriormente, de modo a evidenciar como as imagens, os fatos visuais sugerem associações mnemônicas, ressalta como Tarkovski de $O$ Espelho "incorpora o tempo ao espaço" (FAURE, 1992, p. 14), o que, para Faure, é uma marca do cinema ao tornar 0 tempo "uma dimensão do espaço" (FAURE, 1992, p. 14). Certamente, o espaço estrutura relações temporais. No cinema calcado em narrativas actanciais e na continuidade temporal, no cinema por Burch denominado "modo de representação institucional", esta relação se 
dá de forma mais linear. Em O Espelho, esta construção é de outra ordem.

\section{Amor e $O$ Espelho não negam a inserção da} narrativa no espaço, são duas facetas de sua construção. 0 primeiro filme utiliza a acumulação de informações de uma única locação para situar 0 espectador; 0 segundo, a fragmentação narrativa de uma locação principal habitada por intervenções diversas, para construir um labirinto de significados para os espaços apresentados.

Jafar Panahi enfatiza no documentário sobre sua impossibilidade de filmar - Isto não é um filme (2011) - as implicações do espaço, e de sua falta, para a realização cinematográfica. 0 cineasta usa sua casa para continuar a trabalhar como cineasta. Cumpre pena de prisão domiciliar e está proibido de sair de casa e exercer sua profissão de diretor. Confinado em sua residência, Panahi registra 0 que está à sua volta: sua casa, seu animal de estimação, suas conversas telefônicas e 0 tempo diante de si, quando todos os membros da família se ausentam para enfrentar o cotidiano. No entanto, ele sonha, e seus sonhos se referem à sua cinematografia e projetos futuros. Ignorando as proibições as quais o impediram de exercer sua profissão, Panahi tenta reconstruir com poucos recursos o filme em curso, quando foi privado de sua liberdade.

Em uma sequência de Isto não é um filme, ele tenta representar em sua sala os muros pertencentes à casa onde deveria filmar. Utilizando- se de fita adesiva, traça no chão a planta baixa da locação visitada meses antes. Em um primeiro momento, ele explica ao espectador 0 ambiente e a ação, do local ali sugerido por sua descrição. Panahi relembra seus posicionamentos de câmera e a maneira como gostaria de filmar. Ao mesmo tempo, 0 diretor narra 0 enredo a ser filmado, e a falta de liberdade de seu personagem. Descobrimos que a casa que Panahi nos mostra verbalmente é uma prisão domiciliar velada, na qual uma adolescente precisa esconder suas ações, por conta dos costumes repressores de sua família. Ironicamente, é também uma mulher, a avó da personagem a encarregada de vigiar seus passos.

A sequência tem continuidade com 0 diretor nos mostrando um vídeo, provavelmente captado durante uma visita de locação. Em sua casa, Panahi tenta em vão reproduzi-la com as fitas coladas no chão. Este é um momento de revelação e frustração, fica clara a distância entre aquela imagem do local onde deveria acontecer a cena do filme e as linhas traçadas no chão. Sem locação, o projeto de filme se esvai, é um teatro vazio. A tentativa de decupagem a partir de um espaço inexistente mostra-se um fracasso. Ao ser transposta para as linhas traçadas no chão com fita crepe, o diretor se dá conta da impossibilidade de se edificar blocos de tempo sem espaço a ser percorrido. 0 filme que existe para 0 espectador se desenrola no espaço topográfico de sua casa, as imagens mentais de Panahi ali continuam, não se tornam nem mesmo o duplo que o espelho promove, pois aqui não há presença. 
Para além da espacialidade colocada pela representação para a câmera, o espaço de uma casa é marcado simbolicamente. Bachelard explora esta simbologia em La Poétique de L'Espace. A casa é a proteção inicial, é um refúgio e, como tal, é memória. A casa se confunde, em certos aspectos, com nosso próprio corpo. Sem casa, sem referência visual, haveria filme de ficção? Um antifilme ou metafilme, como em Jogo de Cena (2007), de Eduardo Coutinho, e Isto Não é um Filme. Bachelard explora exemplos em que os recônditos de um lar podem desempenhar papéis semelhantes ao de nosso inconsciente. A memória como espiral do tempo, como aconteceu com Tarkovski, ou a memória de uma vida, como na casa-mausoléu em Amor, onde a continuidade espacial tem como companhia a descontinuidade da vida, o fim do tempo, e em O Espelho, os espaços visualmente contínuos são descontínuos temporalmente, se desfazem para se refazer, plano a plano. Em suma, o tempo ganha camadas no espaço, o tempo se coloca prenhe de futuros e passados pela ocupação do espaço.

\section{Referências}

AUMONT, Jacques. As teorias dos cineastas. Trad: Marina Appenzeller. Campinas, SP: Papirus, 2004. 0 olho interminável

(cinema e pintura). Tradução Eloisa Araújo Ribeiro. SP: Cosac\&Naify, 2004.

BALTRUSAITIS, Jurgis. El espejo. Ensayo sobre una leyenda científica. Revelaciones, ciéncia-ficción y falácias. Madrid: Miraguano, 1978.

DELEUZE, Gilles. A imagem-tempo. 1ª reimpressão. São Paulo: Brasiliense, 2005.
. 0 Ato de criação. Folha de São

Paulo. 27/06/1999. Tradução de José Marcos Macedo. Palestra de 1987.

ELSAESSER, Thomas. Cinema Mundial: Realismo, evidência, presença. In: MELLO, Cecília (org.).

Realismo Fantasmagórico. São Paulo: Pró-Reitoria de Cultura e Extensão Universitária/USP, 2015.

FAURE, Elie. De la Cinéplastique. In: L’Arbre d'éden. Crès, 1922.

MACHADO, Arlindo. A ilusão especular. Uma teoria da fotografia. São Paulo: Gustavo Gili, 2015.

PENDERGRAST, Mark. Mirror. A history of the human love affair with reflection. NY: Basic Books. Perseus Books Group, 2003.

TARKOVSKI, Andrei. Esculpir o tempo. $2^{\text {a }}$ ed. São Paulo: Martins Fontes. 1998. 


\section{The interweaving of space and time} in the films Love and The mirror

\section{Abstract}

While presenting and discussing the time and space bulding strategies in the films Love by Michael Haneke and The mirror by Andrei Tarkvoski, we intend to discuss the use of long-take and relate stylistic strategies that bring on the interweaving of space and time as a mnemonic source.

\section{Keywords}

Space. Time. Long-take. Michael Haneke. Andrei Tarkovski.

\section{El entrecruzamiento del espacio e del} tiempo en los filmes Amory El espejo

\section{Resumen}

Al presentar y discutir estrategias para la construcción del espacio y del tiempo en las películas Amor de Michael Haneke y El espejo de Andrei Tarkovski, buscamos problematizar el uso del plano secuencia y relacionar las distintas estrategias de estilo en que el ubicamiento de espacio y tiempo es recurso mnemónico.

\section{Palabras clave}

Espacio. Tiempo. Plan-sequencia. Michael Haneke, Andrei Tarkovski. 


\section{Expediente}

A revista E-Compós é a publicação científica em formato eletrônico da Associação Nacional dos Programas de Pós-Graduação em Comunicação (Compós). Lançada em 2004, tem como principal finalidade difundir a produção acadêmica de pesquisadores da área de Comunicação, inseridos em instituições do Brasil e do exterior.

\section{E-COMPÓS I www.e-compos.org.br I E-ISSN 1808-2599}

Revista da Associação Nacional dos Programas de Pós-Graduação em Comunicação.

Brasília, v.20, n.1, jan./abr. 2017.

A identificação das edições, a partir de 2008, passa a ser volume anual com três números.

Indexada por Latindex I www.latindex.unam.mx

\section{CONSELHO EDITORIAL}

Alda Cristina Silva da Costa, Universidade Federal do Pará, Brasil Alfredo Luiz Paes de Oliveira Suppia, Universidade Estadual de Campinas, Brasil Álvaro Larangeira, Universidade Tuiuti do Paraná, Brasil Ana Carolina D. Escosteguy, Pontifícia Universidade Católica do Rio Grande do Sul, Brasil Ana Regina Barros Rego Leal, Universidade Federal do Piauí, Brasil Ana Carolina Rocha Pessôa Temer, Universidade Federal de Goiás, Brasil Andrea França, Pontifícia Universidade Católica do Rio de Janeiro, Brasil André Luiz Martins Lemos, Universidade Federal da Bahia, Brasil Angela Cristina Salgueiro Marques, Faculdade Cásper Libero, Brasil Ângela Freire Prysthon, Universidade Federal de Pernambuco, Brasil Antonio Carlos Hohlfeldt, Pontifícia Universidade Católica do Rio Grande do Sul, Brasil Arthur Ituassu, Pontifícia Universidade Católica do Rio de Janeiro, Brasil Bruno Campanella, Universidade Federal Fluminense, Brasil Cláudio Novaes Pinto Coelho, Faculdade Cásper Líbero, Brasil Carlos Eduardo Franciscato, Universidade Federal de Sergipe, Brasil Denise Tavares da Silva, Universidade Federal Fluminense, Brasil Eduardo Vicente, Universidade de São Paulo, Brasil Eliza Bachega Casadei, Escola Superior de Propaganda e Marketing - SP, Brasil Elizabeth Nicolau Saad Corrêa, Universidade de São Paulo, Brasil Erick Felinto de Oliveira, Universidade do Estado do Rio de Janeiro, Brasil Erly Vieira Júnior, Universidade Federal do Espirito Santo, Brasil Francisco de Assis, FIAM-FAAM Centro Universitário, Brasil Francisco Elinaldo Teixeira, Universidade Estadual de Campinas, Brasil Frederico de Mello Brandão Tavares, Universidade Federal de Ouro Preto, Brasil Gabriela Reinaldo, Universidade Federal do Ceará, Brasil Gilson Vieira Monteiro, Universidade Federal do Amazonas, Brasil Gustavo Daudt Fischer, Universidade do Vale do Rio dos Sinos, Brasil Igor Sacramento, Fundação Oswaldo Cruz, Brasil Itania Maria Mota Gomes, Universidade Federal da Bahia, Brasil Jiani Adriana Bonin, Universidade do Vale do Rio dos Sinos, Brasil José Afonso da Silva Junior, Universidade Federal de Pernambuco, Brasil
José Luiz Aidar Prado, Pontifícia Universidade Católica de São Paulo, Brasil Juçara Gorski Brittes, Universidade Federal de Ouro Preto, Brasil Laura Loguercio Cánepa, Universidade Anhembi Morumbi, Brasil Liziane Soares Guazina, Universidade de Brasilia, Brasil Luíza Mônica Assis da Silva, Universidade Católica de Brasília, Brasil Maria Ataide Malcher, Universidade Federal do Pará, Brasil Maria Elisabete Antonioli, Escola Superior de Propaganda e Marketing - SP, Brasil Maria das Graças Pinto Coelho, Universidade Federal do Rio Grande do Norte, Brasil Marcel Vieira Barreto Silva, Universidade Federal da Paraíba, Brasil Marcia Tondato, Escola Superior de Propaganda e Marketing, Brasil Marli Santos, Universidade Metodista de São Paulo, Brasil Márcio Souza Gonçalves, Universidade do Estado do Rio de Janeiro, Brasil Mauricio Mario Monteiro, Universidade Anhembi Morumbi, Brasil Mauricio Ribeiro da Silva, Universidade Paulista, Brasil Mauro de Souza Ventura, Universidade Estadual Paulista, Brasil Mayka Castellano, Universidade Federal Fluminense, Brasil Micael Maiolino Herschmann, Universidade Federal do Rio de Janeiro, Brasil Mozahir Salomão Bruck, Pontifícia Universidade Católica de Minas Gerais, Brasil Nísia Martins Rosario, Universidade Federal do Rio Grande do Sul, Brasil Potiguara Mendes Silveira Jr, Universidade Federal de Juiz de Fora, Brasil Raquel Ritter Longhi, Universidade Federal de Santa Catarina, Brasil Regiane Regina Ribeiro, Universidade Federal do Paraná, Brasil Roberto Elísio dos Santos, Universidade Municipal de São Caetano do Sul, Brasil Rodolfo Rorato Londero, Universidade Estadual de Londrina, Brasil Sérgio Luiz Gadini, Universidade Estadual de Ponta Grossa, Brasil Simone Maria Andrade Pereira de Sá, Universidade Federal Fluminense, Brasil Simone Maria Rocha, Universidade Federal de Minas Gerais, Brasil Suzana Reck Miranda, Universidade Federal de São Carlos, Brasil Tarcyanie Cajueiro Santos, Universidade de Sorocaba, Brasil Tatiana Oliveira Siciliano, Pontifícia Universidade Católica do Rio de Janeiro, Brasil Veneza Mayora Ronsini, Universidade Federal de Santa Maria, Brasil

\section{CONSELHO CIENTÍFICO}

Cristiane Freitas Gutfreind, Pontifícia Universidade Católica do Rio Grande do Sul, Brasil Eduardo Morettin, Universidade de São Paulo, Brasil

Felipe Costa Trotta, Universidade Federal Fluminense, Brasil Irene de Araújo Machado, Universidade de São Paulo, Brasil

\section{COMISSÃO EDITORIAL}

Eduardo Antonio de Jesus, Universidade Federal de Minas Gerais, Brasil Marco Antonio Roxo da Silva, Universidade Federal Fluminense, Brasil Osmar Gonçalves dos Reis Filho, Universidade Federal do Ceará, Brasil

\section{CONSULTORES AD HOC}

Kelly C. de Souza Prudencio, Universidade Federal do Paraná, Brasil Francisco P. Jamil A. Marques, Universidade Federal do Paraná, Brasil Tiago Quiroga F. Neto, Universidade de Brasília, Brasil

\section{EQUIPE TÉCNICA}

ASSISTENTE EDITORIAL Márcio Zanetti Negrini REVISÃO DE TEXTOS Press Revisão EDITORAÇÃO ELETRÔNICA Roka Estúdio IMAGEM DE CAPA Silas de Paula

\section{COMPÓS I www.compos.org.br}

Associação Nacional dos Programas de Pós-Graduação em Comunicação

Presidente

Edson Fernando Dalmonte

Programa de Pós-Graduação em Comunicação

e Cultura Contemporânea - UFBA

edsondalmonte@uol.com.br

Vice-presidente

Cristiane Freitas Gutfreind

Programa de Pós-Graduação em Comunicação Social - PUC-RS cristianefreitas@pucrs.br

Secretário-Geral

Rogério Ferraraz

Programa de Pós-Graduação em Comunicação

Universidade Anhembi Morumbi

rogerioferraraz@anhembimorumbi.edu.br

CONTATO I revistaecompos@gmail.com 